\title{
Distal Right Coronary Artery Conduit
}

National Cancer Institute

\section{Source}

National Cancer Institute. Distal Right Coronary Artery Conduit. NCI Thesaurus. Code C102296.

The section of the right coronary artery distal to the origin of the acute marginal artery. 